\title{
UNCOUPLED VIBRATIONS IN FUNCTIONALLY GRADED TIMOSHENKO BEAM
}

\author{
Nguyen Ngoc Huyen ${ }^{1}$, Nguyen Tien Khiem ${ }^{2, ~ * ~}$ \\ ${ }^{1}$ Thuy Loi University, 175 Tay Son, Dong Da, Hanoi \\ ${ }^{2}$ Vietnam Academy of Science and Technology, 18 Hoang Quoc Viet, Cau Giay, Hanoi \\ "Email: ntkhiem@imech.ac.vn; khiemvch@gmail.com
}

Received: 21 January 2016; Accepted for publication: 20 September 2016

\begin{abstract}
Free vibration of FGM Timoshenko beam is investigated on the base of the power law distribution of FGM. Taking into account the actual position of neutral plane enables to obtain general condition for uncoupling of axial and flexural vibrations in FGM beam. This condition defines a class of functionally graded beams for which axial and flexural vibrations are completely uncoupled likely to the homogeneous beams. Natural frequencies and mode shapes of uncoupled flexural vibration of beams from the class are examined in dependence on material parameters and slenderness.
\end{abstract}

Keywords: FGM, Timoshenko beam; Modal analysis; Coupled vibrations.

\section{INTRODUCTION}

The functionally graded material (FGM) that usually composes of metal and ceramic constituents has been proved to be an advanced composite compared to the layered ones. The fundamentals of manufacturing technology, modeling and analysis of that material were reviewed in [1 - 2]. Though the powerful methods such as finite element [3 - 5], dynamic stiffness [6] and spectral element [7] have been all developed for analysis of FGM structures, the analytical method has still remained the most efficient tool for dynamic analysis of beam-like FGM structures. Aydogdu and Taskin [8] have examined different high-order shear deformation theories by computing natural frequencies of simply supported functionally graded beam and shown that the classical beam theory gives higher results. Li [9] developed a theory of functionally graded Timoshenko beam neglecting the axial displacement and used to study flexural waves and free vibration of Timoshenko beam. Pradhan and Chakraverty [10] studied natural frequencies of both Euler-Bernoulli and Timoshenko functionally graded beams in dependence on material power-law exponent using Rayleigh-Ritz method. Authors of Ref. [11] investigated effect of slenderness ratio $(L / h)$ and the power-law exponent $(n)$ on natural frequencies of a functionally graded beam using the first-order shear deformation theory of beam. Wei et al. [12] and Aydin [13] studied free vibration of functionally graded beam with edge cracks and dynamic responses of functionally graded beams to moving loads were obtained in $[14,15]$. Note that most of the aforementioned theories developed for dynamic analysis of 
functionally graded beam are based on the assumption that neutral plane coincides with the midplane of beam. This is not true for functionally graded beam, especially, in the case of high gradient of elasticity. Recently, Eltaher et al. [16] have studied effect of exact position of neutral axis on natural frequencies of functionally graded Euler-Bernoulli beam and stated that the midplane theory of FGM beam leads natural frequencies to be overestimated. The authors of present paper have investigated material constants calculated for functionally graded Timoshenko beam based on the neutral-plane theory [17] and shown that coupling of axial and flexural vibrations in FGM beam is strongly dependent on the material parameters. Nevertheless, the coupling of axial and flexural vibrations in FGM beam, to the authors' knowledge, has not been thoroughly studied.

Objective of this study is to investigate uncoupled vibrations in functionally graded Timoshenko beam. Namely, the dynamic problem is first formulated for functionally graded Timoshenko beam taking into account the actual position of neutral axis. This enables to obtain general condition for uncoupling of axial and flexural vibration in FGM Timoshenko beams. Numerical analysis of modal parameters of uncoupled flexural vibration is carried out to illustrate and validate the proposed theoretical development.

\section{UNCOUPLED VIBRATION CONDITION}

Consider a beam of length $L$, cross-section area $A=b \times h$ made of FGM with the parameters varying accordingly to the power law

$$
\left\{\begin{array}{l}
E(z) \\
G(z) \\
\rho(z)
\end{array}\right\}=\left\{\begin{array}{l}
E_{b} \\
G_{b} \\
\rho_{b}
\end{array}\right\}+\left\{\begin{array}{l}
E_{t}-E_{b} \\
G_{t}-G_{b} \\
\rho_{t}-\rho_{b}
\end{array}\right\}\left(\frac{z}{h}+\frac{1}{2}\right)^{n},-h / 2 \leq z \leq h / 2,
$$

where $\mathrm{E}, \mathrm{G}$ and $\rho$ stand for elasticity, shear modulus and material density and indexes $t$ and $b$ denote the top and bottom materials; $z$ is ordinate of the point from the central axis at high $h / 2$. Assuming linear theory of deformation the displacement fields in the cross-section at $x$ are

$$
u(x, z, t)=u_{0}(x, t)-\left(z-h_{0}\right) \theta(x, t) ; w(x, z, t)=w_{0}(x, t),
$$

with $u_{0}(x, t), w_{0}(x, t)$ being the axial and flexural displacements of neutral axis that is located at the high $h_{0}$ from the central axis; $\theta$ is slope of the cross-section. Therefore, constituting equations get the form

$$
\varepsilon_{x}=\partial u_{0} / \partial x-\left(z-h_{0}\right) \partial \theta / \partial x ; \gamma_{x z}=\partial w_{0} / \partial x-\theta
$$

and

$$
\sigma_{x}=E(z) \varepsilon_{x} ; \tau_{x z}=\kappa G(z) \gamma_{x z} .
$$

Using Hamilton principle equations of motion can be derived for free vibration as

$$
\begin{gathered}
\left(I_{11} \ddot{u}-A_{11} u^{\prime \prime}\right)-\left(I_{12} \ddot{\theta}-A_{12} \theta^{\prime \prime}\right)=0 ; \\
\left(I_{12} \ddot{u}-A_{12} u^{\prime \prime}\right)-\left(I_{22} \ddot{\theta}-A_{22} \theta^{\prime \prime}\right)+A_{33}\left(w^{\prime}-\theta\right)=0 ; \\
I_{11} \ddot{w}-A_{33}\left(w^{\prime \prime}-\theta^{\prime}\right)=0,
\end{gathered}
$$

where 


$$
\begin{gathered}
\left(A_{11}, A_{12}, A_{22}\right)=\int_{A} E(z)\left(1, z-h_{0},\left(z-h_{0}\right)^{2}\right) d A ; A_{33}=\kappa \int_{A} G(z) d A ; \\
\left(I_{11}, I_{12}, I_{22}\right)=\int_{A} \rho(z)\left(1, z-h_{0},\left(z-h_{0}\right)^{2}\right) d A .
\end{gathered}
$$

Based on the power law (2.1) for FGM the constants (2.6) can be calculated as follow

$$
\begin{gathered}
A_{11}=b h E_{b} F_{1}\left(R_{1}\right) ; A_{12}=b h^{2} E_{b} F_{2}\left(R_{1}\right) ; A_{22}=b h^{3} E_{b} F_{3}\left(R_{1}\right) ; A_{33}=b h \psi G_{b} F_{1}\left(R_{3}\right) ; \\
I_{11}=b h \rho_{b} F_{1}\left(R_{2}\right) ; I_{12}=b h^{2} \rho_{b} F_{2}\left(R_{2}\right) ; I_{22}=b h^{3} \rho_{b} F_{3}\left(R_{2}\right) ; \\
F_{1}(x)=\frac{(x+n)}{(1+n)} ; F_{2}(x)=\frac{2 x+n}{2(2+n)}-\frac{x+n}{(1+n)} \alpha ; F_{3}(x)=\frac{3 x+n}{3(3+n)}-\frac{2 x+n}{(2+n)} \alpha+\frac{x+n}{(1+n)} \alpha^{2} ; \\
R_{1}=E_{t} / E_{b} ; R_{2}=\rho_{t} / \rho_{b} ; R_{3}=G_{t} / G_{b} ; \alpha=1 / 2+h_{0} / h .
\end{gathered}
$$

It can be seen from Eq. (2.5) that the coefficient $A_{12}, I_{12}$ characterize coupling of axial and flexural vibrations. Indeed, under the condition

$$
I_{12}=A_{12}=0,
$$

the first equation in (2.5) is uncoupled with two next ones. Note that if neutral axis is assumed to be coincident with the central one, i. e. $\alpha=1 / 2$ the uncoupling condition (2.8) leads to either $n=0$ or $R_{1}=R_{2}=1$. This implies that axial and flexural vibrations are uncoupled only for homogeneous beam. However, taking account of exact position of neutral axis determined in [16] as

$$
\bar{h}_{0}=h_{0} / h=\frac{n\left(R_{1}-1\right)}{2(n+2)\left(n+R_{1}\right)},
$$

the coefficient $A_{12}=0$ and

$$
\bar{I}_{12}=\frac{I_{12}}{b h^{2} \rho_{b}}=\frac{\left(R_{2}-R_{1}\right) n}{2(2+n)\left(R_{1}+n\right)} .
$$

Therefore, axial and flexural vibrations may be uncoupled not only for homogeneous beam, when $n=0$ but also for FGM beam such that

$$
R_{1}=R_{2} \text {. }
$$

This type of functionally graded material can be called proportional for which

$$
\frac{A_{11}}{I_{11}}=\frac{E_{t}}{\rho_{t}}=\frac{A_{22}}{I_{22}}=\frac{E_{b}}{\rho_{b}}=C_{a}^{2} .
$$

Under the conditions (2.12) equations of uncoupled axial and flexural vibrations are reduced to

$$
\begin{gathered}
\ddot{u}-C_{a}^{2} u^{\prime \prime}=0 ; \\
\ddot{\theta}-C_{a}^{2} \theta^{\prime \prime}-\Omega_{2}^{2}\left(w^{\prime}-\theta\right)=0 ; \ddot{w}-\Omega_{1}^{2}\left(w^{\prime \prime}-\theta^{\prime}\right)=0 ; \\
\Omega_{2}^{2}=A_{33} / I_{22} ; \Omega_{1}^{2}=A_{33} / I_{11} .
\end{gathered}
$$


Eq. (2.13) describes axial vibration of an equivalent homogeneous beam with constant wave speed $C_{a}$ and purely flexural vibration of FGM beam is governed by Eq. (2.14). Note that the purely flexural vibration of a FGM beam was studied in [9] by neglecting axial displacement ( $u=0$ ), but it is not exactly $\left(R_{1} / R_{2}=1.03\right.$ ) uncoupled flexural vibration of the proportional functionally graded (PFG) beam what is subject of subsequent sections

\section{FREE UNCOUPLED VIBRATION}

Since the theory of axial vibration described by Eq. (2.13) for homogenous beam has been well developed, in the present work only uncoupled flexural vibration governed by Eq. (2.14) is investigated. Thus, seeking solution of Eq. (2.14) in the form

$$
\theta(x, t)=\Theta(x) e^{i \omega t} ; w(x, t)=W(x) e^{i \omega t},
$$

one gets

$$
\left(\omega^{2} I_{22} \Theta+A_{22} \Theta^{\prime \prime}\right)+A_{33}\left(W^{\prime}-\Theta\right)=0 ; \omega^{2} I_{11} W+A_{33}\left(W^{\prime \prime}-\Theta^{\prime}\right)=0 .
$$

Using the following vector $\mathbf{z}=\{\Theta, W\}^{T}$ and matrices

$$
\mathbf{A}_{2}=\left[\begin{array}{cc}
A_{22} & 0 \\
0 & A_{33}
\end{array}\right] ; \mathbf{A}_{1}=\left[\begin{array}{cc}
0 & A_{33} \\
-A_{33} & 0
\end{array}\right] ; \mathbf{A}_{0}=\left[\begin{array}{cc}
\omega^{2} I_{22}-A_{33} & 0 \\
0 & \omega^{2} I_{11}
\end{array}\right] ;
$$

Eq. (3.3) can be rewritten in the matrix form

$$
\mathbf{A}_{2} \mathbf{z}^{\prime \prime}+\mathbf{A}_{1} \mathbf{z}^{\prime}+\mathbf{A}_{0} \mathbf{z}=0 .
$$

Now, seeking solution of Eq. (3.4) in the form $\mathbf{z}_{0}=\mathbf{d} e^{\lambda x}$ leads the equation to

$$
\left[\lambda^{2} \mathbf{A}_{2}+\lambda \mathbf{A}_{1}+\mathbf{A}_{0}\right] \mathbf{d}=0 .
$$

The latter equation would have nontrivial solution with respect to constant vector $\mathbf{d}$ under the condition

$$
\operatorname{det}\left[\lambda^{2} \mathbf{A}_{2}+\lambda \mathbf{A}_{1}+\mathbf{A}_{0}\right]=0
$$

that can be expressed in the form

$$
\lambda^{4}+a \lambda^{2}+b=0
$$

where

$$
a=\omega^{2}\left(I_{11} / A_{33}+I_{22} / A_{22}\right) ; b=\left(\omega^{2} I_{11} / A_{33}\right)\left(\omega^{2} I_{22} / A_{22}-A_{33} / A_{22}\right) .
$$

In general, equation (3.7) is elementarily solved and gives in result

$$
\lambda_{1,2}^{2}=\left(-a \pm \sqrt{a^{2}-4 b}\right) / 2=\eta_{1,2} .
$$

Note first that Eq. (3.7) would have trivial root $(\lambda=0)$ under the condition

$$
\omega=\omega_{c}=\sqrt{A_{33} / I_{22}}=\Omega_{2},
$$

termed as cutoff frequency of the beam. Otherwise, the Eq. (3.7) has all four imaginary roots for $\omega>\omega_{c}$ and two real roots if $\omega<\omega_{c}$. Hence, four roots of Eq. (3.7) are 


$$
\lambda_{1,3}= \pm k_{1} ; \lambda_{2,4}= \pm k_{2} ; k_{j}=\sqrt{\eta_{j}}, j=1,2
$$

and general solution of Eq. (3.4) can be represented as

$$
\mathbf{z}=\left\{\begin{array}{c}
\Theta \\
W
\end{array}\right\}=\left\{\begin{array}{l}
d_{11} e^{k_{1} x}+d_{12} e^{k_{2} x}+d_{13} e^{-k_{1} x}+d_{14} e^{-k_{2} x} \\
d_{21} e^{k_{1} x}+d_{22} e^{k_{2} x}+d_{23} e^{-k_{1} x}+d_{24} e^{-k_{2} x}
\end{array}\right\} .
$$

Taking into account the second equation in (3.2) one gets

$$
d_{21}=\alpha_{1} d_{11}, d_{22}=\alpha_{2} d_{12}, d_{23}=-\alpha_{1} d_{13}, d_{24}=-\alpha_{2} d_{14},
$$

where

$$
\alpha_{1}=k_{1} A_{33} /\left(\omega^{2} I_{11}+k_{1}^{2} A_{33}\right), \alpha_{2}=k_{2} A_{33} /\left(\omega^{2} I_{11}+k_{2}^{2} A_{33}\right) .
$$

Therefore, expression (3.12) can be now rewritten in the form

$$
\mathbf{z}(x, \omega)=\mathbf{G}(x, \omega) \mathbf{d},
$$

with $\mathbf{d}=\left(d_{1}, \ldots, d_{4}\right)^{T}=\left(d_{11}, \ldots, d_{14}\right)^{T}$ and

$$
\begin{gathered}
\mathbf{G}(x, \omega)=\left[\mathbf{G}_{1}(x, \omega) \mathbf{G}_{2}(x, \omega)\right] ; \\
\mathbf{G}_{1}(x, \omega)=\left[\begin{array}{cc}
e^{k_{1} x} & e^{k_{2} x} \\
\alpha_{1} e^{k_{1} x} & \alpha_{2} e^{k_{2} x}
\end{array}\right] ; \mathbf{G}_{2}(x, \omega)=\left[\begin{array}{cc}
e^{-k_{1} x} & e^{-k_{2} x} \\
-\alpha_{1} e^{-k_{1} x} & -\alpha_{2} e^{-k_{2} x}
\end{array}\right] .
\end{gathered}
$$

The solution (3.15) should fulfill conditions at the ends of the beam that can be represented in the form

$$
\left.\mathbf{B}_{0}\{\mathbf{z}\}\right|_{x=0}=0 ;\left.\mathbf{B}_{\mathrm{L}}\{\mathbf{z}\}\right|_{x=L}=0,
$$

where $\mathbf{B}_{0}, \mathbf{B}_{\mathrm{L}}$ are differential operators of dimension $2 \times 2$. For instance, the operators $\mathbf{B}_{0}, \mathbf{B}_{\mathrm{L}}$ for conventional boundary conditions for respectively simple support; clamp and free end would be

$$
\mathbf{B}_{s}=\left[\begin{array}{cc}
-A_{22} \partial_{x} & 0 \\
0 & 1
\end{array}\right] ; \mathbf{B}_{c}=\left[\begin{array}{cc}
1 & 0 \\
0 & 1
\end{array}\right] ; \mathbf{B}_{e}=\left[\begin{array}{cc}
-A_{22} \partial_{x} & 0 \\
-A_{33} & A_{33} \partial_{x}
\end{array}\right] \text {. }
$$

Now, decomposing the vector $\mathbf{d}=\left\{\mathbf{d}_{1}, \mathbf{d}_{2}\right\}^{T}$ with $\mathbf{d}_{1}=\left\{d_{1}, d_{2}\right\}^{T} ; \mathbf{d}_{2}=\left\{d_{3}, d_{4}\right\}^{T}$ the condition at the left end of beam can be expressed as

$$
\mathbf{B}_{01} \mathbf{d}_{1}+\mathbf{B}_{02} \mathbf{d}_{2}=0
$$

where

$$
\mathbf{B}_{01}(\omega)=\left.\mathbf{B}_{0}\left\{\mathbf{G}_{1}(x, \omega)\right\}\right|_{x=0} ; \mathbf{B}_{02}(\omega)=\mathbf{B}_{0}\left\{\mathbf{G}_{2}(x, \omega)\right\}_{x=0} .
$$

Obviously, Eq. (3.18) allows eliminating one of the vectors $\mathbf{d}_{1}, \mathbf{d}_{2}$ and as result one is able to reconstruct the solution $\mathbf{z}(x)$ as

$$
\mathbf{z}(x, \omega)=\mathbf{G}_{0}(x, \omega) \mathbf{D}
$$

with $\mathbf{G}_{0}(x, \omega)$ being $2 \times 2$ dimension matrix function and arbitrary constant vector $\mathbf{D}=\left\{D_{1}, D_{2}\right\}^{T}$. Applying boundary conditions at the other end $(x=L)$ of beam for solution (3.19) one gets 


$$
\begin{gathered}
{\left[\mathbf{G}_{L}(\omega)\right]\{\mathbf{D}\}=0 ;} \\
\left.\mathbf{G}_{\mathrm{L}}(\omega)=\mathbf{B}_{\mathrm{L}}\left\{\mathbf{G}_{0}(x, \omega)\right\}\right\}_{x=L} .
\end{gathered}
$$

This equation has nontrivial solution only under the condition

$$
L_{0}(\omega)=\operatorname{det}\left[\mathbf{G}_{L}(\omega)\right]=0,
$$

that provides the so-called frequency equation for FGM beam. Each root $\omega_{j}$ of the frequency equation is related to a mode shape

$$
\Phi_{j}(x)=C_{j} \mathbf{G}_{0}\left(x, \omega_{j}\right) \overline{\mathbf{D}}_{j},
$$

where $C_{j}$ is an arbitrary constant and $\overline{\mathbf{D}}_{j}$ is the normalized solution of (3.18) with $\omega=\omega_{j}$.

\section{RESULTS AND DISCUSSIONS}

In this section numerical analysis is examined for PFG beam with the initial material parameters [9]: Steel: $E_{b}=210 G P a, \rho_{b}=7850 \mathrm{~kg} / \mathrm{m}^{3}, \mu_{1}=0.3$ (bottom surface) and shear module is calculated as $G=E / 2(1+\mu)$. The material parameters of the top surface are calculated from those of bottom with proportional ratio $r: E_{t}=r E_{b} ; \rho_{t}=r \rho_{b}$. Under the analysis the dimensionless natural frequencies $\bar{\omega}_{j}=\left(\omega_{j} L^{2} / h\right) \sqrt{\rho_{b} / E_{b}}$ and related mode shapes are examined in dependence on the proportional ratio; exponent of the power law, $n$ (called here material distribution index) and the shear modulus ratios $\gamma=G_{t} / G_{b}=r\left(\mu_{2}+1\right) /\left(\mu_{1}+1\right)$.

First, natural frequencies of homogenous Timoshenko simply supported beam are computed and compared to those obtained in Ref. [6] by the dynamic stiffness method and in Ref. [18] by analytical method. It can be observed excellent agreement of the results that consequently verify the proposed above theory.

Table 1. Comparison of natural frequencies for homogeneous Timoshenko beam.

\begin{tabular}{|c|c|c|c|c|c|c|c|c|}
\hline \multirow{2}{*}{$\begin{array}{c}\text { Freq. } \\
\text { No }\end{array}$} & Present & Ref. [18] & Ref. [6] & Present & Ref. [18] & Ref. [6] & Present & Ref. [18] \\
\hline 1 & 2.8020 & 2.8020 & 2.8023 & 2.8438 & 2.8438 & 2.8439 & 2.8486 & 2.8486 \\
\hline 2 & 10.6948 & 10.6947 & - & 11.3116 & 11.3116 & - & 11.3887 & 11.3887 \\
\hline 3 & 15.6092 & 15.7080 & - & 25.2184 & 25.2184 & - & 25.6046 & 25.6046 \\
\hline \multicolumn{8}{|c|}{$\mathrm{E}=70 \mathrm{GPa}, \rho=2700 \mathrm{~kg} / \mathrm{m}^{3}, \mu=0.3$} \\
\hline
\end{tabular}

\subsection{Cutoff frequency analysis}

Cutoff frequency (3.10) computed as function of proportional ratio in various material distribution index and slenderness is shown in Figs. 1-2. It can be observed from the Figures that cutoff frequency is monotonically increasing with proportional ratio larger 1 for $n \leq 5$ and it is decreasing with growing $r$ for $n>5$. Obviously, cutoff frequency of homogenous beam is constant and it is rapidly increasing with beam slenderness $\mathrm{L} / \mathrm{h}$. Moreover, for a fixed material 
distribution index cutoff frequency is weakly dependent on the proportional ratio; the dependence is almost linear for $n=50$ and strongly nonlinear for $n=2$.

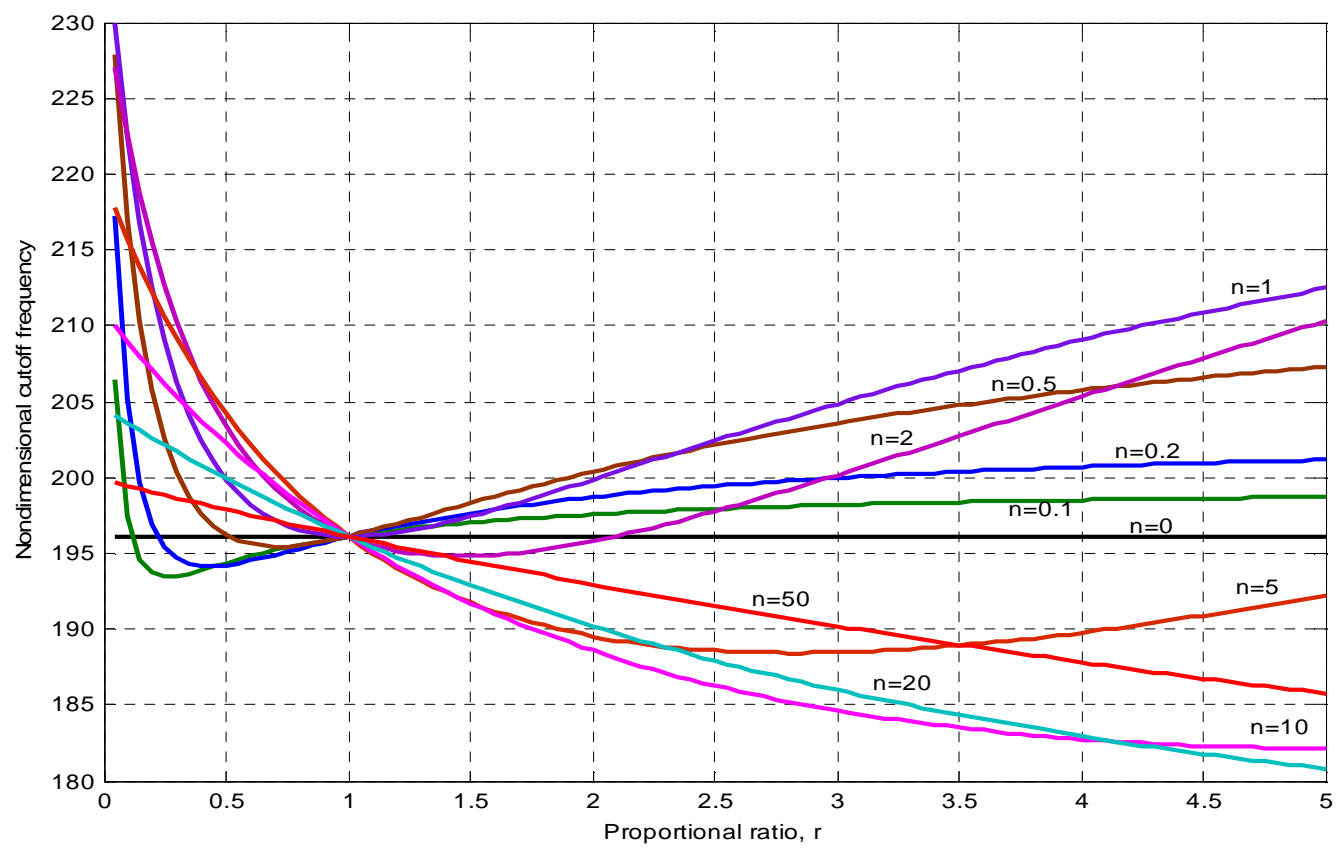

Figure 1. The uncoupled cutoff frequency vs. proportional ratio for various material distribution index $n$.

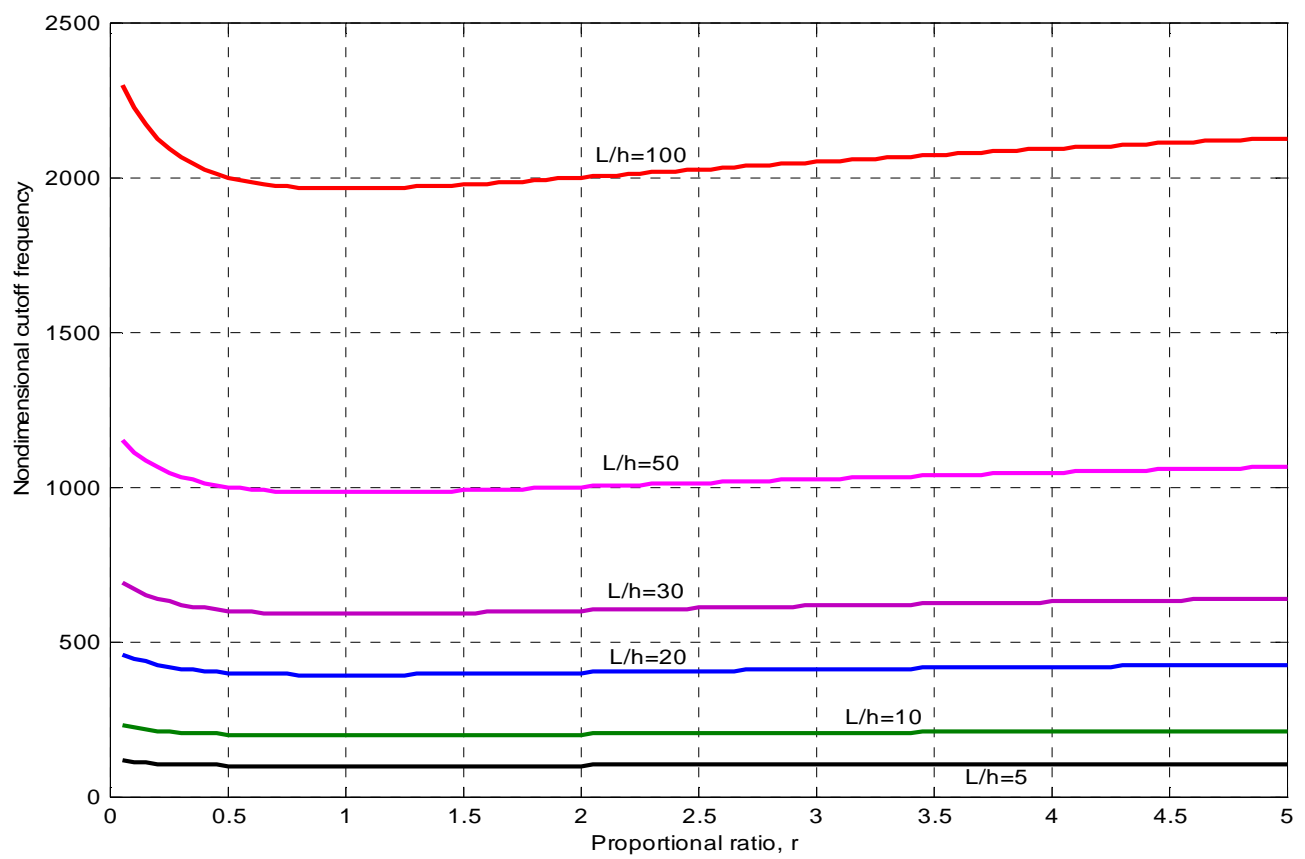

Figure 2. The uncoupled cutoff frequency vs. proportional ratio for various slenderness $\mathrm{L} / \mathrm{h}$.

\subsection{Natural frequency analysis}




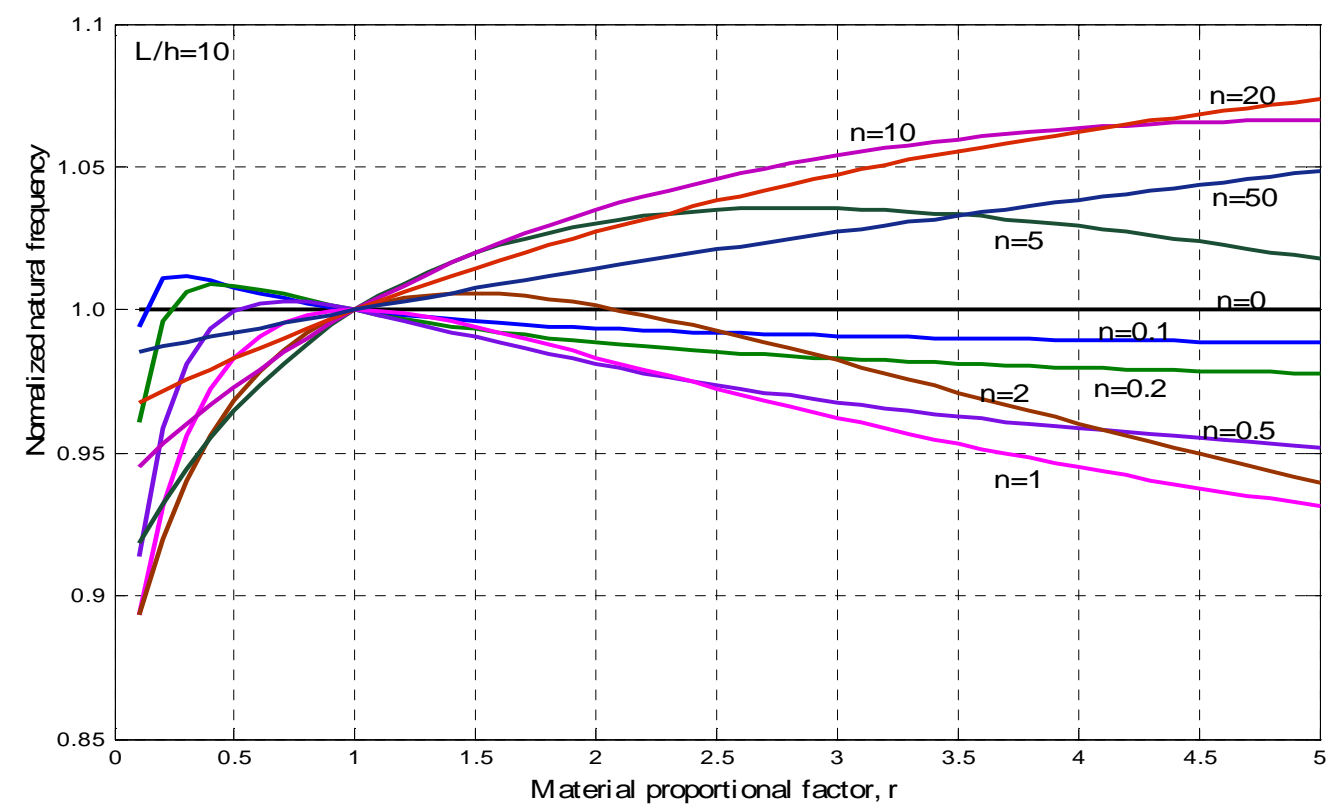

Figure 3. Normalized uncoupled flexural frequency of FGM beam in dependence on the proportional factor $r$ in various material distribution index $n$.

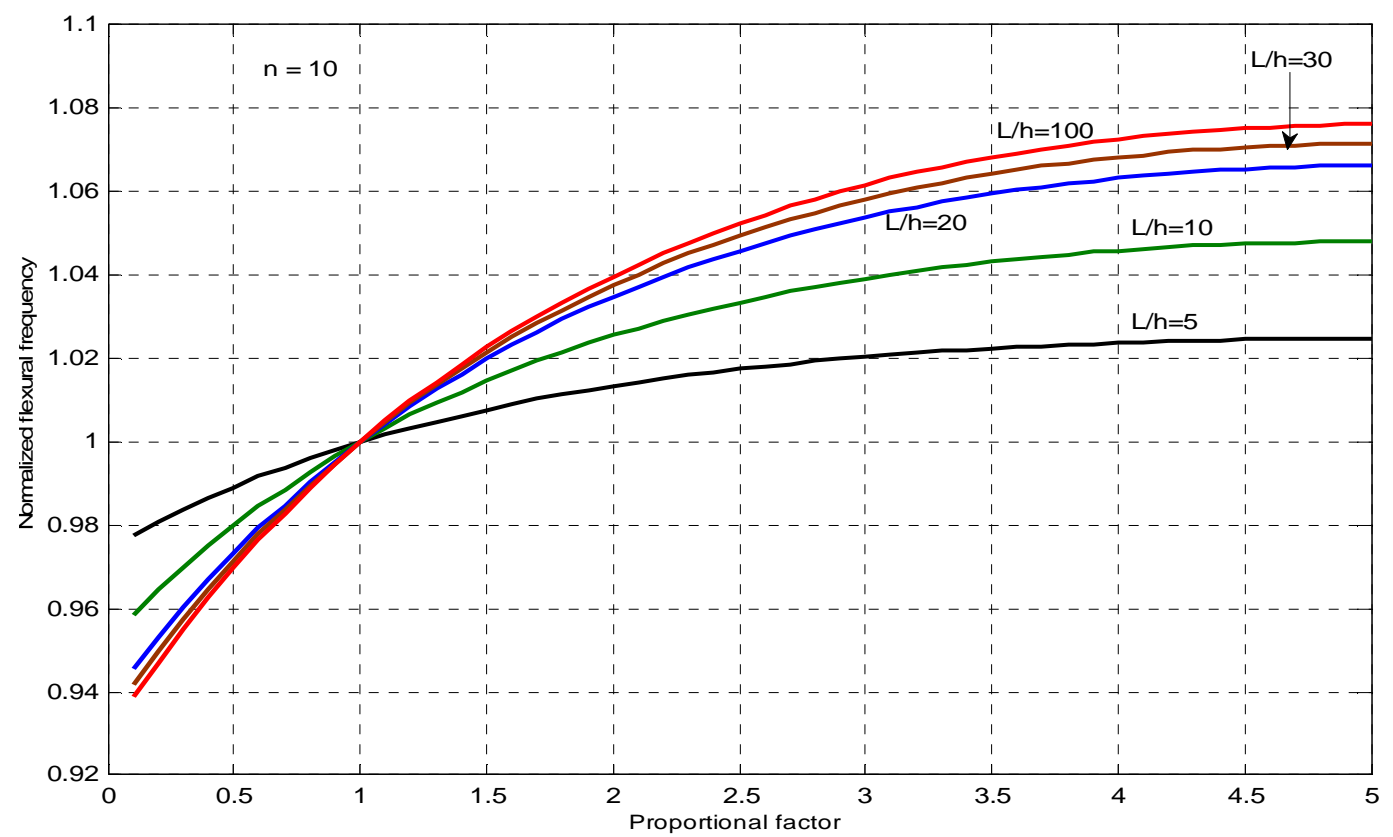

Figure 4. Normalized uncoupled flexural frequency of FGM beam in dependence on the proportional factor $R$ in various slenderness $L / h$.

Typical variation of natural frequencies versus proportional ratio is shown in Figs. 3-4,in which there are presented natural frequencies normalized by those of homogeneous beam $(r=1)$. It can be seen that flexural natural frequencies of PFG beam are limited to the range (0.9-1.1) times of the frequencies of homogeneous beam. They are less than those of homogeneous beam when $n<5$ and become greater for $n \geq 5$. The linear dependence of 
natural frequencies on proportional ratio gets to be if $n=50$. Normalized natural frequencies are all monotonically increasing with slenderness for $r>1$ and decreasing for $r<1$.

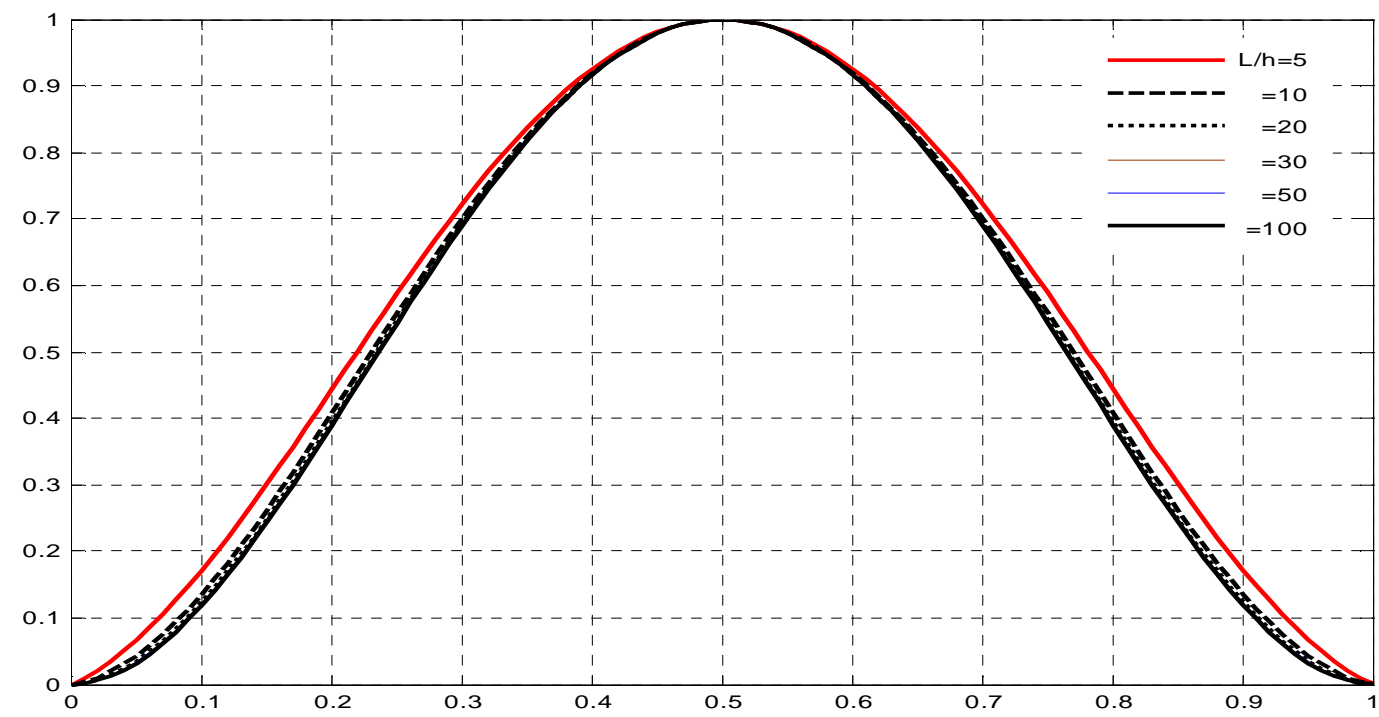

Figure 5. First mode shape in dependence on the slenderness L/h.

\subsection{Mode shape analysis}

Numerical analysis shows that mode shapes of the PFG beam are not affected by material parameters such as proportional ratio $r$ and material distribution index $n$. They may be slightly modified by various slenderness of the beam what is demonstrated in Figs. 5-7 where first three mode shapes of clamped functionally graded Timoshenko beam are presented.

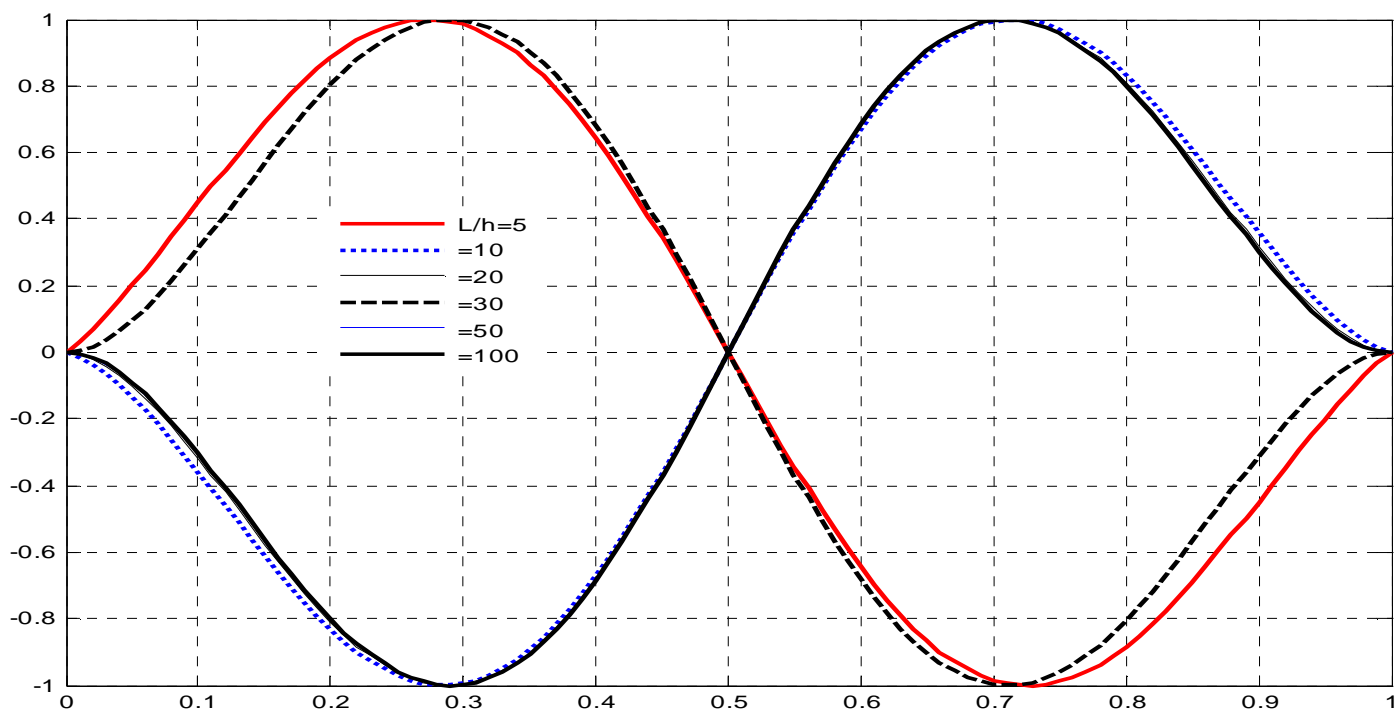

Figure 6. Second mode shape in dependence on the slenderness L/h. 


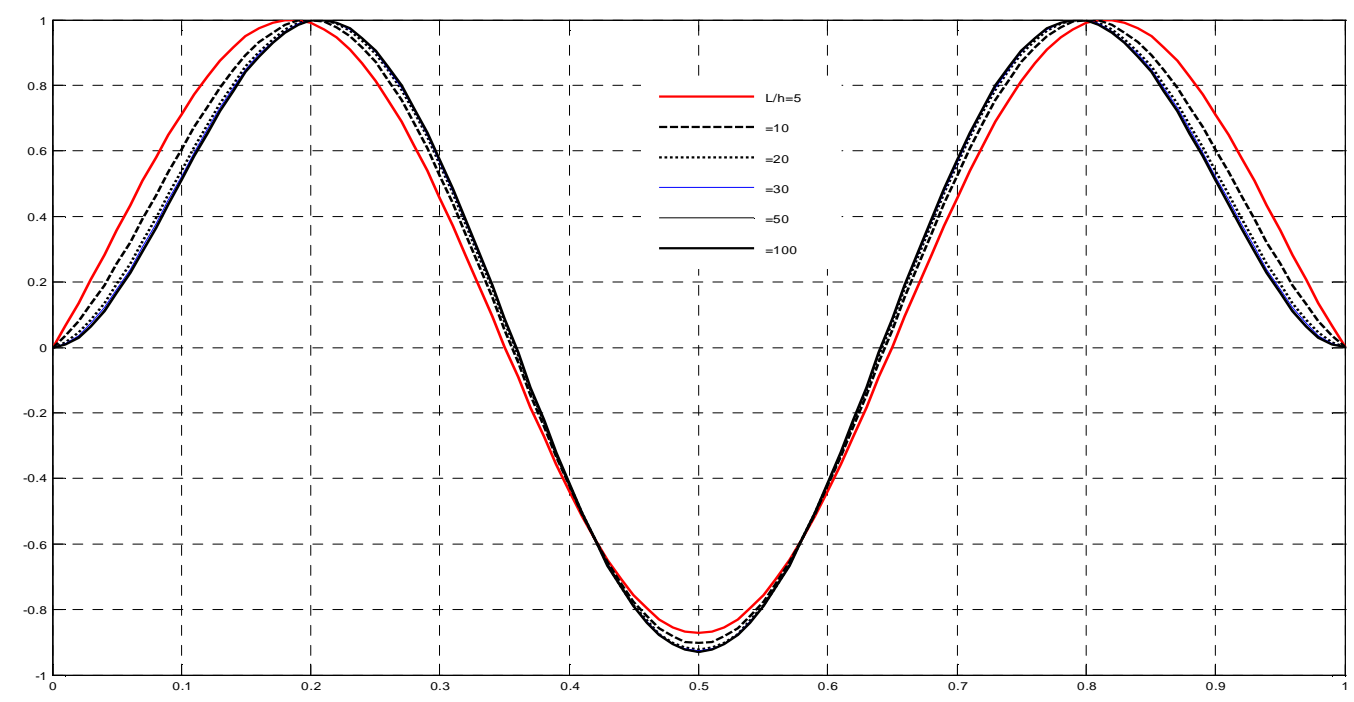

Figure 7. Third mode shape in dependence on the slenderness $\mathrm{L} / \mathrm{h}$.

\section{CONCLUSION}

The main results obtained in present study are as following:

1. In the framework of the proposed theory of vibration for functionally graded beam based on true position of neutral plane, a condition for uncoupling of axial and flexural vibration modes has been obtained.

2. It was shown that uncoupled axial vibration of such the beam remains completely similar to that of homogeneous beam.

3. Numerical analysis has demonstrated that natural frequencies including the cutoff frequency in uncoupled flexural vibration are typically dependent on the material and geometrical parameters of the beam.

4. Mode shapes of the uncoupled flexural vibration are insensitive to material parameters; they are dependent only on slenderness of the functionally graded beam.

5. All the above mentioned concluding remarks provide useful instructions for modal testing and identification of functionally graded beam. Moreover, the obtained natural frequencies of an FGM beam in dependence on the material properties enable one to control not only the vibration characteristics but also the stiffness and material density of the beam.

Acknowledgements. This work was completed under support from NAFOSTED of Vietnam, Grant No. 107.01-2015.20, to whom the authors are sincerely thankful.

\section{REFERENCES}

1. Suresh S. and Mortensen A. - Fundamentals of Functionally Graded Materials. ASM International and the Institute of Materials, Cambridge, 1995.

2. Birman V. and Byrd L. W. - Modeling and Analysis of Functional Graded Materials and Structures, Applied Mechanics Reviews 60 (2007) 195-215. 
3. Chakraborty A., Gopalakrishnan S. and Reddy J. N. - A new beam finite element for the analysis of functional graded materials, International Journal of Mechanical Science 45 (2003) 519-539.

4. Alshorbagy A. E., Eltaher M. A. and Mahmoud F. F. - Free vibration characteristics of a functionally graded beam by finite element method, Applied Mathematical Modelling 35 (1) (2011) 412-425.

5. Nguyen D. K. - Large displacement response tapered cantilever beam made of axially functionally graded material, Composite Part B: Engineering 55 (2013) 298-305.

6. Su H. and Banerjee J. R. - Development of dynamic stiffness method for free vibration of functionally graded Timoshenko beams, Computers and Structures 147 (2015) 107-116.

7. Chakraborty A. and Gopalakrishnan S. A. - Spectrally formulated finite element for wave propagation analysis in functionally graded beams, International Journal of Solids and Structures 40 (2003) 2421-2448.

8. Aydogdu M. and Taskin V. - Free vibration analysis of functionally graded beams with simply supported edges, Material and Design 28 (2007) 1651-1656.

9. Li X. F. - A unified approach for analyzing static and dynamic behaviors of functionally graded Timoshenko and Euler-Bernoulli beams, Journal of Sound and Vibration $\mathbf{3 1 8}$ (2008) 1210-1229.

10. Pradhan K. K. and Chakraverty S. - Free vibration of Euler and Timoshenko functionally graded beams by Rayleigh-Ritz method, Composite: Part B 51 (2013) 175-184.

11. Sina S. A., Navazi H. M. and Haddadpour H. - An analytical method for free vibration analysis of functionally graded beams, Materials and Design 30 (2009) 741-747.

12. Wei D., Liu Y. H. and Xiang Z. H. - An analytical method for free vibration analysis of functionally graded beams with edge cracks, Journal of Sound and Vibration 331 (2012) 1685-1700.

13. Aydin K. - Free vibration of functional graded beams with arbitrary number of cracks, European Journal of Mechanics A/Solid 42 (2013) 112-124.

14. Simsek M. and Kocatuk T. - Free and forced vibration of a functionally graded beam subjected a concentrated moving harmonic load, Composite Structures 90 (4) (2009) 465473.

15. Yang J., Chen Y., Xiang Y. and Jia X. L. - Free and forced vibration of cracked inhomogeneous beams under an axial force and a moving load, Journal of Sound and Vibration 312 (2008) 166-181.

16. Eltaher M. A., Alshorbagy A. E. and Mahmoud F. F. - Determination of neutral axis position and its effect on natural frequencies of functionally graded macro/nano-beams, Composite Structures 99 (2013) 193-201.

17. Khiem N. T. and Huyen N. N. - On the neutral axis of FGM beam, Proceedings of National Conference on Engineering Mechanics, Da Nang - Vietnam, Aug. 3-5, 2015 (in Printing).

18. Karnovsky I. A. and Lebed O. I. - Formulas for Structural Dynamics: Tables, Graphs and Solutions. McGraw-Hill, Inc, 2001. 


\title{
TÓM TẮT
}

\section{DAO ĐỘNG TÁCH RỜI CỦA DÂM TIMOSHENKO CÓ CƠ LÍ TÍNH BIẾN THIÊN}

\author{
Nguyễn Ngọc Huyên ${ }^{1}$, Nguyễn Tiến Khiêm² \\ ${ }^{1}$ Đại học Thủy lợi, 175 Tây Sơn, Đống Đa, Hà Nội \\ ${ }^{2}$ Viện Co học, Viện HLKHCNVN, 18 Hoàng Quốc Việt, Cầu Giấy, Hà Nội \\ "Email: ntkhiem@imech.ac.vn; khiemvch@gmail.com
}

Bài báo này nghiên cứu dao động riêng của dầm Timoshenko có cơ lí tính biến đổi theo quy luật lũy thừa. Việc tính đến vị trí thực của trục trung hòa (không phải là trục giữa dầm) cho phép ta nhận được điều kiện để dao động dọc trục và dao động uốn tách rời nhau (trở nên độc lập) giống như dầm đồng nhất. Tuy nhiên các tham số của các dạng dao động tách rời đó vẫn là của dầm có cơ lí tính biến thiên (chứ không phải của dầm đồng nhất). Ở đây, nghiên cứu tần số và dạng riêng trong dao động uốn tách rời của dầm FGM phụ thuộc vào các tham số vật liệu và hình học.

Tù khóa: Vật liệu cơ lí tính biến thiên, dầm Timoshenko, phân tích dao động, dao động quan liên 